Kymlicka, W. (1995) Multicultural Citizenship: A Liberal Theory of Minority Rights, Oxford: Oxford University Press.

Levey, A. (2000) 'Liberalism, adaptive preferences, and gender equality' Hypatia, Vol. 15, No. 4: 127-143.

Okin, S.M. (1999) 'Is multiculturalism bad for women?' in Cohen, J., Howard, M. and Nussbaum, M. (1999) editors, Is Multiculturalism Bad for Women? Princeton: Princeton University Press.

Sunstein, C. (1992) 'Neutrality in constitutional law (with special reference to pornography, abortion, and surrogacy)' Columbia Law Review, Vol. 92, No. 1: 1-52.

Yuracko, K. (2003) Perfectionism and Contemporary Feminist Values, Bloomington: Indiana University Press.

doi: $10.1057 / \mathrm{fr} .2008 .32$

\title{
Trans/forming feminisms: trans-feminist voices speak out
}

Krista Scott-Dixon, editor; Sumach Press, Toronto, 2006, 255pp., ISBN - 13 978-1-894549-61-5, ISBN - 10 1-894549-61-9, £17.50

This collection centres around the question of which experiences and struggles trans and feminist political projects share, asking 'how might trans and feminist ideas inform future struggles for social justice and the enhancement of human dignity' (p. 12). Editor Scott-Dixon is refreshingly open and honest in her introduction as she positions herself in relation to this politic. She uses a social and political model of difference and self-identification rather than a model situated within scientific and medical discourses that have historically classified and systematized gendered and sexed bodies and lived experiences, seeing social structures and environments as being the things that present obstacles, rather than individuals having the 'problem', deficit or 'disorder'. This is a perspective that opens up a healthy space for debate and discussion and the collection is an eclectic array of contributions. The diversity manifests in a range of pitch, subject matter, style, tone, tenor and readership. It includes personal narrative, utopian wishing for a world without gender, and angry venting, as well as theoretically robust analyses of essentialist positions, specific subjectivities, and ideological state apparatuses such as the law. There are 27 pieces from 25 different authors and such a plethora of perspectives is interesting, but it makes this a book to dip-in-and-out of. This is a smorgasbord or appetizer of transfeminist voices - some you'll leave to one side and others, you know you'll order as a 'main course' in the near future.

Daryl B. Hill's chapter 'On the Origins of Gender' in the opening section 'Narratives \& Voices' draws on various trans people's understanding of the 
essentialist/constructivist dialectic in relation to their own lived experience. The discussion of the personal is framed such that lived experiences are drawn upon in relation to specific models of understanding gender. This is a simple but useful explication. Of further note, Pershai's 'The Language Puzzle: Is Inclusive Language a Solution?' unpicks the notion of 'linguistic deficiency' and the concept of inclusive language regarding trans. Pershai advocates caution around categorization when talking about trans-feminist experience for fear that 'new' terms or ways of utilizing personal pronouns should become mandatory, thereby maintaining an (albeit extended) hegemonic language system.

Scott-Dixon introduces Section 2, which focuses on debates around the borders of community, and the ways that difference exists within categories of identity. The various contributions here call for inclusion and support among the trans community, by way of challenging some of the hierarchies operant within it as a way of moving forward to demand and expect inclusion, respect, and equality from other sectors of society, not withstanding mainstream feminism. Reese Simpkins, for example, explores the complexity of legitimacy for trans men within the 'masculine hierarchy'. Susan Driver looks at trans relationships, placing the emphasis on the nature and value of the interpersonal, of intimacy, sensuality, sexuality, and love.

Gilbert's 'The Feminist Cross-Dresser' seems to undo some of these challenges to hierarchizing. The chapter centres around a dichotomy of man and woman, boy and girl, in terms of the way people are perceived, valued, and judged by those around them. Gilbert asserts that girls 'learn about style, clothing, makeup and carriage from each other... and the exemplars of popular icons and their styles' whereas boys are 'lucky if they come out of adolescence knowing what matches' (pp. 107-108). I would suggest that thinking of the category 'boy' in such a monolithic way is not helpful. Boy-ness is as multi-faceted as the masculinities that Simpkins alludes to, so for example some boys - let's say white British working class boys living in London - are increasingly drawn into a culture that values image and currency in terms of the fashion and body industries to the extent where they too are objectified, just as Gilbert's 'girls' are. This point is therefore moot.

Gilbert is calling for people who cross dress, and wear so-called 'women's' clothing, to cultivate a feminist perspective, but suggests that this will primarily involve developing a heightened awareness of negative possibilities built around fear. This includes being vulnerable and feeling unsafe when walking down a street - a feeling that Gilbert tells us, 'happens to women all the time' (p. 111). Gilbert suggests that in wearing high-heeled shoes, a cross-dresser is able to consciously process the insight that this discomfort gives - an insight into women's lived experience. 
One of the delights of the book is the sense one gets when reading, of engaging in debate with the 'group' of voices present. This is a virtual kind of debate, which shifts with each short, sharp encounter. An excellent example of where two chapters argue directly with each other is in Section 3 'Inclusion \& Exclusion', with the juxtaposition of Sreedhar and Hand's 'The Ethics of Exclusion: Gender and Politics at the Michigan Womyn's Music Festival' and Niki's 'Women's Spaces are Not Trans Spaces: Maintaining Boundaries of Respect'.

The former contains a provocative call to exclude trans women from buildings, services (such as a rape crisis centre), and spaces set up for women because of, for example, rape survivors' potential 'terror at the presence and display of a penis' ( $p .156$ ), and is called to account by a perspective in the latter that would rather move to a self-identification model when categorizing woman: ' $[W]$ omanhood is a constellation of anatomical, psychological, experiential and phenomenological properties, none of which is even arguably necessary or sufficient for womanhood' (Sreedhar and Hand, p. 166). This for me is one of the clearest and most straightforward (and at the same time, beautifully paradoxical) statements in the collection and one that supports Scott-Dixon's opening call to reveal social structures and environments as being the things that present obstacles to an equitable lived experience for all, rather than individuals being the 'problem'.

Catherine McNamara

doi: $10.1057 /$ fr. 2008.28

\section{Tackling the roots of racism: lessons for success}

Reena Bhavnani, Heidi Safia Mirza and Veena Meetoo, in association with the Joseph Rowntree Foundation; Policy Press, Bristol, UK, 2005, 230pp., ISBN 1-861-3477-4X, £15.99 pbk

Thirty years on from the Race Relations Act, racism remains alarmingly rife in British society, and the complexities of race and racism are still areas that command serious debate. Despite these complexities, scholars observe the often formulaic and tokenistic thinking, and misguided oversimplification that often accompanies such debates. During the years since the Race Relations Act, Britain has seen the emergence of a plethora of policies, procedures and initiatives proposing strategies for the reduction of racism. However, as the authors astutely observe there has been little research conducted to examine whether the results of such initiatives have lived up to prior expectations. While many 